\title{
Afterword: From Sustainable Development to Environmental Governance
}

\author{
Eduardo Silva
}

This collection represents a milestone in the political ecology of environmental governance in Latin America. Given the enduring tension between the environment and development, its overarching purpose in my reading of the text is to elucidate the headway, obstacles and potential of our times to achieving the aspirations and goals of sustainable development, particularly in some of its early versions. Because this is a highly contested concept, and one that some of the contributors to this volume would most likely reject, I use it heuristically. It offers a platform from which to discuss the necessity of environmental governance that genuinely addresses environmental protection, social equity and broad-based political participation in the context of (largely) capitalist development; and this, in my view, is the central subject of the book.

Much has changed in the world since the Brundtland Commission first launched the idea of sustainable development in the mid-1980s: the end of the Soviet Bloc, free-market globalization, the rise of emerging market economies and profound transformations in manufacturing processes, just to name a few. Latin America transitioned to democratic governments, it benefited from sustained economic growth in the 2000s with some improvement in poverty alleviation, and it weathered a world recession. The region also witnessed an unexpected resurgence of the left. Left governments that would have been targets for decisive destabilization by the USA during the Cold War have successfully asserted their sovereignty, survived, and even thrived in some cases. This volume asks: What is the significance of these changes for advances in environmental governance that seriously addresses the problem of environmental 
sustainability beyond end-of pipe treatment, that supports and promotes sustainability of livelihoods by subordinate peoples, and that offers meaningful political participation in the context of the current stage of capitalist development?

The first significant contribution of this book is that it moves us substantially closer towards establishing an empirical baseline on where we stand with respect to these vital questions. In my reading, the overall tenor of the chapters is this. For all of the region's economic prosperity over the past decade and relative success in reducing poverty, pushing up the salience of the environmental issue area in the policy process with an emphasis on alternative technologies, livelihoods and meaningful participation from below has not gained much political traction. Indeed, in some cases we even see backsliding.

That said, the volume establishes that there have been advances in pushing up the salience of the environmental issue area in general. This is no small matter given the very low priority that environmental issues had for political leaders grappling with debt, economic restructuring, political instability and the imperatives of finding their way to a stable development model in the 1970s and 1980s. Today, no major stakeholders in government, business, civil society or academia take a cornucopian hands-off human ingenuity and the price system shall provide position (see Chapter 6). Although many believe in the imperative of development, they acknowledge that environmental concerns cannot be ignored.

The terrain then logically shifts to questions regarding the contested meanings of development, social equity, environmental sustainability and broad-based political participation; the competing conceptualizations of relations of domination and subordination in society embedded in those meanings; and their social, political, economic and cultural distributional consequences. In short, the book starts from the right place: the classic questions of what type of development, and development for whom.

The collection's political ecology approach points us in a fruitful direction to tackle these questions. The editors start from the analytic distinction that I, and others, made long ago between market-based and livelihood or bottom-up grassroots development models of sustainable development (Silva, 1994, 1997). To this they add a neodevelopmental model born of the left turn in Latin American governments, which features a return of the state and economic nationalism in development policy. The ascent of left governments initially fuelled expectations that the alternative approaches to the environment and development would, 
at last, find favourable political support after decades of market dominance. The book, in an unflinching yet realistic analysis, accounts for hopes dashed.

The volume's more significant contribution, however, is that it reveals a more complex reality. It shows how those left governments straddle various approaches, how they juggle or mix them. On the one hand, the neodevelopmental state plays a larger role in the economy and society than a neoliberal state, but it accepts market dictates such as GM organisms, carbon swaps, a focus on public and private nature conservation, and the expansion of megaextractive projects in mining, agribusiness and energy. On the other hand, some states under left government rule challenge the market-oriented approach that dominates the international climate-control regime. Moreover, although left governments fight anti-megaproject protests, they do not always ram them through no matter what the consequences. At times they cancel projects. More optimistically, the book also reminds us that states are not unitary rational actors. Agencies, departments and even a ministry or two may support projects and policies that advance alternative, livelihoods approaches to the environment and development. Since states operate in the context of democratic regimes, organized subaltern groups and their communities can ally with supportive agencies to survive and, in a few instances, grow. At minimum the struggle continues.

In addition to these advances in the characterization of contemporary environmental governance in Latin America, we also gain an elegant picture of the logic behind its current construction in chapters 2, 4 and 5. Latin American states, their governments, elites, class structures and, of course, economies are part of a world capitalist system, and generally in a subordinate position within it. Absent revolutionary breakdowns of existing polities, market-oriented and supportive development policies in general, and environmental policies specifically, are logically the norm and incremental reforms at the margin are about the most we can expect. The state is organized accordingly.

The collection makes it clear that it is within this context that we need to understand unquestionable advances in institutional capacitybuilding in the environmental issue area. The environment is firmly on the policy agenda. All Latin American states have built up ministries, agencies and departments for the environment. The technical knowledge and the national and international networks of their professional staff have expanded by leaps and bounds over the past 30 years. Their infrastructural reach has intensified. But they are at the service of states and dominant elites that must respond to the vicissitudes 
of world markets for their continued reproduction and development. Thus environmental protection regimes have improved by instituting environmental impact reporting, advances in end-of-pipe treatment, adoption of polluter pays principles, and nature conservation. However, we should not be surprised that they are consonant with market or neodevelopmental approaches to environmental sustainability that often disregard questions of social sustainability or that, at best, only seek to compensate - usually poorly and belatedly - for losses to adversely affected communities.

The book drives home a further telling point. How do at least nominally progressive governments juggle these contradictions? By using the commodity boom to substantially expand their welfare effort in social assistance, education, health and infrastructure development. Many of these welfare policies are now reaching not only the urban poor but, significantly, the rural poor. Some governments have also concentrated on substantially raising minimum wages. Thus previously marginalized peoples, at least statistically, have been lifted out of poverty and seen the life chances of their children improve. Judging by electoral returns, governments successfully argue that the aggressive expansion of resource extraction makes these compensatory policies possible.

In short, we gain a concise, well-defined specification of Latin American environmental governance regimes understood as the principles, norms, rules and procedures that infuse governing environmental institutions, their managers, their policies and their operations. This is an important step forward. It clarifies policy agendas and bounds policy prescriptions. It also sets up the relationship of official institutions to society: who's in, under what conditions, and who's out.

This significant contribution to Latin American political ecology is developed in the first half of the volume. The opening chapters, however, stress that Latin American environmentalism is also infused with a widespread, deep-seated concern for livelihoods, environmental justice and alternative production models that is unique to the region (see Chapter 1). These concerns cannot simply be ignored and swept under the carpet. Note to technocratic policy-makers: Resistance to policies that do so is to be expected. To believe otherwise is wishful thinking at best, or an act of willful, arrogant domination at worst.

The second half of the book explores the multifaceted reality of resistance to market and neodevelopmental policies and their lack of social and environmental justice and sustainability. But it does so within the context of a more holistic conceptualization of environmental governance. This permits us to begin to discern the larger significance 
of fragmented, local resistance for the construction of a more inclusive form of environmental governance in Latin America.

Herein lies the second major contribution of the volume to understanding Latin American environmental politics. Governance is generally understood as how the state organizes systems for rule, meaning that citizens obey its maxims, institutions and policies (Weber, 1978). It is also about the state effectively controlling citizen behaviour and instructing its citizens in how to behave properly (Foucault, 1997). In sum, the focus is on the state's capacity to foster and maintain order with a minimum of overt conflict and coercion. Effective governance systems channel societal tensions in ways that minimize open conflict. Ineffective ones fail to do so. Either way, resistance conflict and institutional change are external to the governance regime.

The editors understand this and, as I argued above, do us the service of specifying for the first time how Latin American states and their elites organize for rule in the environmental issue area. But they go further: they argue that resistance, conflict and coercion are not external to governance; they are an integral part of governance. Governance is a dialectic process that involves order and resistance. Understood this way, we can get at the potential sources of institutional change in Latin American environmental governance. This is the crucial issue for those interested in the question of how to open up policy space for concerns about livelihood, social and environmental justice, and alternative, small-scale, ecofriendly environmental policies. Even more importantly, this approach to environmental governance opens up a path to figuring out the broader, cumulative policy and political impacts of fragmented, localized, heterogeneous and territorially marginal protests. I will come back to this theme later.

The book, correctly, underscores two major paths to change. That they are both represented in one volume is rare and permits us to appreciate more the strengths and weaknesses of each. One argues that communities of marginal, subaltern social groups - of which there are many should disengage from the policy process (see Chapter 10). They would be better off devoting their energies and scarce resources to creating their own alternative worlds by practising the principles of solidarity, social justice, freedom, autonomy, and alternative knowledge and production modes they espouse (see Chapter 3). Their multiplication coupled with networking among themselves will corrode the dominant society and force change, either because the dominant society collapses under its own weight or because it must adapt to avoid being overtaken. We see this position most clearly in Chapter 10. Questions remain about 
how those networks might expand, how their experiences can overcome resource deprivation in the midst of more or less functioning capitalist societies, and what the "tipping points" might be. Eventually, these experiences would also have to engage in politics and articulate with other actors, but which and how remains underexamined.

The other potential path for change involves engagement with established political systems at the international, national or subnational scale or combinations of them to effect institutional and policy reforms. For example, national left governments more connected to their social bases may seek to modify international regimes that favour marketoriented policies in ways that accommodate alternative approaches, as seen in Chapter 8 about REDD. By the same token, communities may attempt to use REDD as an opportunity to promote projects with a more alternative, livelihoods cast as described in Chapter 9 about community forestry in Mexico. Perhaps most promising of all was the experience depicted in Chapter 11 of communities making multiscalar alliances with local government, national government agencies and international organizations to organize consultations on unwanted megamining projects promoted by national governments, transnational corporations and multilateral lending institutions. Their application of national and international standards for conducting such extraofficial consultations was inspiring, as was the fact that such campaigns at times contributed to stopping the project.

The weaknesses of engagement with politics are well known. How can one avoid co-optation as leadership loses touch with its social bases? Will engagement merely result in cosmetic or symbolic changes or simply serve to disarticulate environmental justice movements (EJMs)? Will political allies betray such movements? What opportunities must EJMs seek to create in the face of unfavourable structural conditions? How can they scale up successful experiences? These are the perennial hard questions to which we have no good answers. This book, and similar research, suggests that networking analysis, which is gaining increasing attention, might be a fruitful way to go (von Bülow, 2010).

This brings me to a third major contribution of this volume to pushing the frontiers of Latin American political ecology. It offers a cogent and readily apprehensible approach to multiscalar analysis. All too often, analyses of problems that involve multiple scales simply devolve into descriptions of a bewildering multiplicity of actors with different interests and power resources. It becomes difficult to understand the relationship between them and how outcomes are affected. This book, because of the careful groundwork it has laid with respect to 
the specification of dominant governance regimes and its relationship to sources of resistance, overcomes those weaknesses. We understand the logic behind the multiscalar relationships that are forming, breaking apart and reconfiguring, thus we are able to easily follow them and apprehend their significance for the larger questions that stand at the centre of this collection. This is a manageable method that travels well in new and evolving situations.

This is a significant advance because a sign of our times is the increasing complexity of our multiscalar world, its fragmentation, heterogeneity, compartmentalization and segmentation. These characteristics permeate the environmental issue area, exacerbated by its intersection with economic, political and social structures. It is also one of the few arenas in our contemporary stage of capitalism where private property rights are hotly contested. This book reminds us that careful specification of ideal types can help us to make sense of the mixed types that exist in reality and the logical consequences for social action that follow from their characteristics. Hybrid types and bricolage cease to be ad hoc descriptive, and often confusing, assemblages, and they acquire real analytical bite.

In sum, this volume makes valuable empirical, conceptual, analytical and methodological contributions to the political ecology of environmental governance. It establishes an empirical benchmark from which to assess change or a lack thereof by carefully specifying actors, interests, power, and the structures and ideational frameworks in which they exist and operate. It provides a theoretical framework grounded in the everyday reality of the vast sea of marginalized peoples caught on the receiving end of harsh systems of domination, systems that are characterized with equal attention to reality. Consequently, the book constitutes an important advance from earlier efforts in Latin American political ecology (Painter and Durham, 1995).

Where do we go from here? This collection points us in fruitful directions. Its specification of the concept of environmental governance and its political ecology operationalization offers an innovative common framework for analysis. But what do we expect from improved environmental governance? Here is a question that merits further exploration. The book proposes that at minimum it should provide spaces for alternative, more ecofriendly approaches to inclusive development. That opens up another persistent problem: how to integrate subaltern social groups in a manner that does not compromise their autonomy, and with alternative forms of ecofriendly, low-impact, small-scale economic production that includes conservation measures. 
Of course, examples of poster projects abound, but the issue is not so much technical as political. What are the conditions under which those isolated experiences might thrive and expand? As I mentioned previously, one path the book points to is the disengagement of marginalized peoples from the political process with a focus on building the alternative world they dream of. This suggests more work on the conditions that facilitate this process and its scaling-up through networking, as well as thinking about tipping points for the dominant society.

Engagement with politics by organized subaltern groups is the other path. I have already suggested the types of research needed to advance further on this front. The larger question, to expand on the point above, involves the conditions under which, in the context of contemporary capitalism, spaces for progressive environmental governance can be created, supported and scaled up to a meaningful proportion. Those who argue for disengagement clearly think it is an impossible proposition. The burden of proof is on those who focus on social movement resistance that engages authorities over time, seeking reforms to existing arrangements.

In an earlier comment I submitted that the book offers some starting points. I would like to expand on that by suggesting that a tighter focus on the outcomes of resistance might be useful. Given the decentred nature of much resistance, asking what the cumulative effects of the multitude of local actions are could be a fruitful research agenda. Understanding the causal mechanisms behind those results would also be advantageous. The classic approach has been to focus on proposed or enacted legislation. However, we must transcend that approach. One research strategy might be to analyse the effects of protest on the different stages of the policy process, such as agenda-setting, initiation, formulation, implementation and evaluation. Going beyond that relatively superficial level, one could also research deeper changes in the distribution of power. This includes significant changes in access to power by subordinate groups, often requiring institutional reforms; diffusion of new values; and improvements in movement resources to support the consolidation of new channels of access to power or new values.

By the same token, we need to improve our understanding of the causal mechanisms that influence those outcomes. Chapter 11 suggests that networking across multiple scales and the appropriation of existing principles, norms, rules and practices for other purposes might be an avenue. We can build on that and other works that focus on networks (von Bülow, 2010), but we must also expand our analytical tools 
to distinguish between direct effects and those mediated by third parties (Silva, 2013). That would advance analysis and contribute to the formulation of innovative strategies and policy proposals.

Expanding these lines of research can help us with another vital issue. An oft-stated goal is to develop the participation of subaltern social groups that demand alternative forms of ecofriendly, small-scale economic production in the policy process. But what constitutes "real" participation and how do we get it? Yes, it must be deliberative and binding, and protest seems to be the only way to advance on this issue, but there is much more to it than that. A more social scientific formulation to guide us might be: How do we specify the dimensions of the concept and the consequences of different participatory mechanisms for containing political tensions, and in whose interest? What combinations of multiscalar action and ideational innovations are conducive to positive results? In this vein it might be useful to think about plausible alternatives or improvements to existing institutions, which might be informal rather than formal (Rodrik, 2007). The alternative consultations analysed in Chapter 11 are an example of this.

This book's approach to environmental governance unequivocally moves the discussion about environment, development and social justice past its current point of relative stagnation. To the extent that it highlights participation, conflict and resistance to environmentally and socially damaging development models it suggests that negotiation is another critical feature of environmental governance. Analysis frequently stresses maximum demands and outcomes benchmarked against them. But we also need to explore intermediate outcomes. Negotiation is about compromise, not capitulation. This raises additional questions worth further research. What are "exploited" actors willing to settle for? What is a second-best option? Where and what are those spaces for negotiation, formal or informal? What role does protest play in the negotiation process? Raising these questions in no way means losing sight of the potential for divisiveness or co-optation of movements when they begin to negotiate with governments or companies.

I conclude with the following brief reflection. Latin American political economy in general (and this collection in particular) focuses on natural resource extraction and the ever-present penetration of capitalism into rural or frontier regions where customary and collective forms of social organization are still relatively strong. Hence the environment is an issue area in which property rights and conceptions about economic, political and social organization are contested in places far from the urban centres. Moreover, with increasing frequency, indigenous 
cosmologies, presuming their affinity with nature, are invoked. What about environmental problems in urban areas? Do appeals to indigenous cosmology help or hinder? How does it travel to urban centres? These questions notwithstanding, is there a way to harness a dispossessed urban social subject around environmental issues in ways that facilitate alliances with rural actors? We know from history that ruralurban alliances of popular sectors tend to have greater power in pushing more radical reforms. Is it possible to construct such alliances for environmental governance along the lines this book advocates? It might be wishful thinking but the question is worth asking for the problem of environment and development is not only a rural one; it affects all. We know very little about the urban side of the equation. Perhaps we should re-examine our assumptions.

\section{References}

Brundtland Commission (1987) Our Common Future (New York: Oxford University Press).

Painter, M. and Durham, W.H. (eds) (1995) The Social Causes of Environmental Destruction in Latin America (Ann Arbor: The University of Michigan Press).

Rodrik, D. (2007) One Economy, Many Recipies: Globalization, Institutions, and Economic Growth (Princeton: Princeton University Press).

Silva, E. (1994) "Thinking Politically About Sustainable Development in the Tropical Forests of Latin America", Development and Change 25 (4): 697-721.

Silva, E. (1997) "The Politics of Sustainable Development: Native Forest Policy in Chile, Venezuela, Costa Rica, and Mexico", Journal of Latin American Studies 29 (2): 457-493.

Silva, E. (2013) "Protest and Policy Change", paper presented at the American Political Science Convention, Chicago, Illinois, August 29-31.

Von Bülow, M. (2010) Building Transnational Networks: Civil Society and the Politics of Trade in Latin America (New York: Cambridge University Press).

Weber, M. (1978) Economy and Society (Berkeley: University of California Press).

Except where otherwise noted, this work is licensed under a Creative Commons Attribution 3.0 Unported License. To view a copy of this license, visit http://creativecommons.org/licenses/by/3.0/ 